Journal of Scientific Perspectives

Volume 3, Issue 2, Year 2019, pp. 119-132

E - ISSN: 2587-3008

URL: http://ratingacademy.com.tr/ojs/index.php/jsp

DOI: https://doi.org/10.26900/jsp.3.013

Research Article

\title{
RSM METHOD AND OPTIMIZATION OF HARD COATED SOFT SUGAR PROCESS PARAMETERS
}

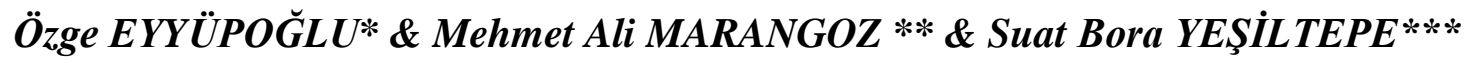 \\ *Durukan Confectionery R\&D Centre, Turkey, E-mail: ozge.eyyupoglu@durukan.com.tr \\ ORCID ID: https://orcid.org/0000-0002-6982-6404 \\ **Durukan Confectionery R\&D Centre, Ankara, Turkey, \\ E-mail: mehmetali.marangoz@durukan.com.tr \\ ORCID ID: https://orcid.org/0000-0002-6209-3172 \\ *** Durukan Confectionery R\&D Centre, Ankara,Turkey, E-mail: bora.yesiltepe@durukan.com.tr \\ ORCID ID: https://orcid.org/0000-0002-6177-091X
}

Received: 26 December 2018; Accepted: 7 March 2019

\begin{abstract}
Nowadays, the textural characteristics of foods affect the consumers' enjoyment about them. Providing ideal textural properties, especially in multi stage food production processes, is a complex and sensitive work that must be carried out with high precision. Hard sugar coated chewy product, "Chewy Drage" is highly preferred by the confectionery consumers all over the world. In this work, the changes in the physical behaviors of "Chewy Drage" with the changes in textural and process parameters was studied. Each process parameter was separately optimized and the relationship between those physical properties was elaborated.
\end{abstract}

Keywords: Chewy Dragee, Candy Manufacturing, Texture

\section{INTRODUCTION}

Texture of a product covers the structural and mechanical properties. Therefore, understanding the mechanical characteristics of a food product is crucial to understand the textural characteristics and measurement techniques of that product.

Texture defining methods are categorized by 3 methods; those are basic, experimental and imitative ones. Basic force/deformation methods are developed according to the engineering bases of the material and are used to measure the known mechanical characteristics of the food. Experimental methods are used successfully to evaluate these mechanical characteristics and to compare the values obtained from the results of the sensory evaluation of the food. Imitative methods are obtained from the simulations of food chewing. There is no single texturing method that can be successfully used for all food products. Thus, determination of the food quality depends on the right method to be chosen. (1-9) 
Confectionery making technology; particularly obtaining a special textural structure is significantly based on the art and science of sugar processing, which are the principal components of the confectionery manufacturing. The most significant factor to obtain the desired quality in confectionery is the control of the crystallization of candy mass and the adjustment of the sugar-water ratio.

In this study, the optimization of production process of "Chewy Dragee" product by using RSM method; and its textural and rheological characterizations were amongst the research topics.

\section{METHOD}

\subsection{Formulation Determination Studies}

In this study, 2 different chewy recipes, with and without gelatin, were tested. The recipes were as shown in the Table 1. and Table 2. in terms of their componenets. The effects of formulation changes on product core structure in the process step scale were examined in the production tests.

Table-1: Prescription 1

\begin{tabular}{|l|l|}
\hline Sugar & \\
\hline Glucose Syrup & \\
\hline Gelatin & \\
\hline Sorbitol & \\
\hline Oecithin & \\
\hline Maltodextrin & \\
\hline Moxtrine & \\
\hline Gms
\end{tabular}

Table-2: Prescription 2

\begin{tabular}{|l|l|}
\hline Sugar & \\
\hline Glucose Syrup & \\
\hline Sorbitol & \\
\hline Lecil & \\
\hline Maltodextrin & \\
\hline Dextrine & \\
\hline Gms
\end{tabular}

\subsection{Process Tests}

\subsubsection{Experimental Design Formation (RSM Work)}

RSM (Response Surface Methodology), is a significant tool used for optimization, high performance operations and product acceptance studies. This optimization method is a statistical technique. The parameters that influence the process are called independent variables and the responses that influences the process are called dependent variables. 
In order to achieve the best optimization conditions, it has been determined in which parameter ranges (lower, middle, and upper values) the work should be done (9).

Experiments based on the independent variables $\mathrm{f}(\mathrm{x})(-1,0,1)$ reveal first degree polynomial equations in response to the dependent variable (y). These equations composed for each process steps helped to optimize the process. The equations that mathematically express the effects of the independent variable on the dependent variable provided both mathematical and experimental observations.

The values expressed as $-1,0,1$ were the lower, upper and middle values of the independent variable in the process step. In this study, 13 testing sets were formed according to these independent variables. Dependent variables were also determined in the end product. These are consistency, viscosity, humidity and color (L, a, b) values.

For each dependent variable, a polynomial equation was formed by the help of RSM technique. Thanks to this equation, it was possible to determine how the change in the process parameters affects to the dependent variable.

\subsubsection{Cooking Tests}

13 testing sets below allowed us to determine the effect of temperature and vacuum variables on the product consistency, product behavior, viscosity, humidity and color properties in optimal values.

Table-3 Cooking Tests Table

\begin{tabular}{|c|c|c|c|c|c|c|c|c|c|c|}
\hline \multicolumn{11}{|c|}{ Cooking Tests } \\
\hline \multirow[b]{2}{*}{$\begin{array}{l}\text { Test } \\
\text { No: }\end{array}$} & \multirow[b]{2}{*}{ Temperature } & \multirow[b]{2}{*}{ Vacuum } & \multirow[b]{2}{*}{$\begin{array}{c}\text { Temperature } \\
\left({ }^{\circ} \mathrm{C}\right)\end{array}$} & \multirow[b]{2}{*}{$\begin{array}{c}\text { Vacuum } \\
\text { (-Bar) }\end{array}$} & \multicolumn{2}{|c|}{ Texture } & \multirow[b]{2}{*}{$\begin{array}{c}\text { Humidity } \\
\text { (\%) }\end{array}$} & \multicolumn{3}{|c|}{ Color } \\
\hline & & & & & $\begin{array}{c}\text { Consistency } \\
\text { (ForcexTime) }\end{array}$ & $\begin{array}{c}\text { Viscosity } \\
\text { Index } \\
\text { (ForcexTime) }\end{array}$ & & $\mathrm{L}^{*}$ & $a^{*}$ & b* $^{*}$ \\
\hline 1 & -1 & -1 & 110 & 0,3 & 7815,12 & 1671,01 & 6,91 & 62,34 & 0,45 & 10,13 \\
\hline 2 & 1 & -1 & 130 & 0,3 & 9291,58 & 2263,73 & 6,44 & 63,50 & 0,47 & 10,50 \\
\hline 3 & -1 & 1 & 110 & 0,7 & 9514,54 & 2125,45 & 6,41 & 62,83 & 0,48 & 10,80 \\
\hline 4 & 1 & 1 & 130 & 0,7 & 11034,51 & 3027,16 & 6,05 & 63,70 & 0,49 & 10,90 \\
\hline 5 & -1 & 0 & 110 & 0,5 & 8745,90 & 1974,02 & 6,74 & 62,90 & 0,46 & 10,53 \\
\hline 6 & 1 & 0 & 130 & 0,5 & 9983,63 & 2265,74 & 6,28 & 63,01 & 0,47 & 10,44 \\
\hline 7 & 0 & -1 & 120 & 0,3 & 8528,86 & 1759,09 & 6,61 & 62,59 & 0,46 & 10,62 \\
\hline 8 & 0 & 1 & 120 & 0,7 & 10234,23 & 3297,13 & 6,41 & 63,97 & 0,49 & 10,70 \\
\hline 9 & 0 & 0 & 120 & 0,5 & 9472,41 & 2080,37 & 6,48 & 62,88 & 0,46 & 10,38 \\
\hline 10 & 0 & 0 & 120 & 0,5 & 9473,30 & 2050,43 & 6,51 & 62,90 & 0,46 & 10,38 \\
\hline 11 & 0 & 0 & 120 & 0,5 & 9459,53 & 2018,73 & 6,48 & 62,85 & 0,46 & 10,40 \\
\hline 12 & 0 & 0 & 120 & 0,5 & 9452,71 & 2060,65 & 6,50 & 62,80 & 0,46 & 10,37 \\
\hline 13 & 0 & 0 & 120 & 0,5 & 9482,60 & 2067,54 & 6,49 & 62,81 & 0,45 & 10,39 \\
\hline
\end{tabular}

*The L value for each scale therefore indicates the level of light or dark, the a value redness or greenness, and the $\mathrm{b}$ value yellowness or blueness. All three values are required to completely describe an object's color. Retrieved from https://www.hunterlab.com on 27.2.2019

\subsubsection{Rapid Cooling Tests}

The rapid cooling step is required for continuous production processes. 13 tests were performed and the mass obtained after cooking was kept at 80-100 $\mathrm{C}$ on the cooling stages. Then, the viscosity index and consistency parameters of the mass obtained were measured. 
Table-4. Rapid Cooling Tests Table

\begin{tabular}{|c|c|c|c|c|c|c|}
\hline \multicolumn{7}{|c|}{ Rapid Cooling Tests } \\
\hline $\begin{array}{c}\text { Test } \\
\text { No. }\end{array}$ & Temperature & Time & Temperature $\left({ }^{\circ} \mathbf{C}\right)$ & $\begin{array}{c}\text { Time } \\
(\text { mins. })\end{array}$ & $\begin{array}{c}\text { Consistency } \\
(\text { ForcexTime) }\end{array}$ & $\begin{array}{c}\text { Viscosity Index } \\
(\text { ForcexTime) }\end{array}$ \\
\hline 1 & -1 & -1 & 80 & 5 & 14325,85 & 4096,60 \\
\hline 2 & 1 & -1 & 100 & 5 & 12149,25 & 5101,66 \\
\hline 3 & -1 & 1 & 80 & 10 & 14685,12 & 3917,77 \\
\hline 4 & 1 & 1 & 100 & 10 & 12614,63 & 4316,72 \\
\hline 5 & -1 & 0 & 80 & 7,5 & 14412,90 & 4718,36 \\
\hline 6 & 1 & 0 & 100 & 7,5 & 12590,71 & 4254,53 \\
\hline 7 & 0 & -1 & 90 & 5 & 13423,73 & 4105,61 \\
\hline 8 & 0 & 1 & 90 & 10 & 13129,20 & 4971,47 \\
\hline 9 & 0 & 0 & 90 & 7,5 & 13285,19 & 4481,95 \\
\hline 10 & 0 & 0 & 90 & 7,5 & 13387,62 & 4410,18 \\
\hline 11 & 0 & 0 & 90 & 7,5 & 13215,38 & 4414,63 \\
\hline 12 & 0 & 0 & 90 & 7,5 & 13242,63 & 4492,23 \\
\hline 13 & 0 & 0 & 90 & 7,5 & 13399,74 & 4406,81 \\
\hline
\end{tabular}

\subsubsection{Crystallization Tests}

This set of experiments allowed us to see the change of sugar amount and time versus texture and color.

Table-5. Crystallization Tests Table

\begin{tabular}{|c|c|c|c|c|c|c|c|c|}
\hline \multicolumn{9}{|c|}{ Crystallization Tests } \\
\hline & & & & \multicolumn{2}{c|}{ Texture } & \multicolumn{3}{c|}{ Color } \\
\hline Crystallization & $\begin{array}{c}\text { Amount } \\
\text { of Sugar }\end{array}$ & Time & $\begin{array}{c}\text { Amount of } \\
\text { Sugar (\%) }\end{array}$ & $\begin{array}{c}\text { Time } \\
\text { (mins.) }\end{array}$ & Strength(g) & L $^{*}$ & $\mathbf{a}^{*}$ & $\mathbf{b}^{*}$ \\
\hline 1 & -1 & -1 & 0,50 & 10 & 1698,74 & 81,21 & 0,50 & 10,08 \\
\hline 2 & 1 & -1 & 10,00 & 10 & 1510,44 & 81,95 & 0,51 & 10,10 \\
\hline 3 & -1 & 1 & 0,50 & 30 & 1490,40 & 80,33 & 0,49 & 10,03 \\
\hline 4 & 1 & 1 & 10,00 & 30 & 1302,30 & 79,10 & 0,53 & 10,39 \\
\hline 5 & -1 & 0 & 0,50 & 20 & 1604,59 & 84,30 & 0,55 & 10,52 \\
\hline 6 & 1 & 0 & 10,00 & 20 & 1403,21 & 80,15 & 0,47 & 10,13 \\
\hline 7 & 0 & -1 & 5,25 & 10 & 1515,55 & 82,99 & 0,48 & 10,15 \\
\hline 8 & 0 & 1 & 5,25 & 30 & 1350,03 & 81,43 & 0,49 & 10,33 \\
\hline 9 & 0 & 0 & 5,25 & 20 & 1453,85 & 83,25 & 0,50 & 10,29 \\
\hline 10 & 0 & 0 & 5,25 & 20 & 1452,25 & 83,78 & 0,51 & 10,32 \\
\hline 11 & 0 & 0 & 5,25 & 20 & 1490,91 & 83,90 & 0,51 & 10,30 \\
\hline 12 & 0 & 0 & 5,25 & 20 & 1450,10 & 83,56 & 0,53 & 10,25 \\
\hline 13 & 0 & 0 & 5,25 & 20 & 1482,44 & 83,45 & 0,52 & 10,15 \\
\hline
\end{tabular}

*The L value for each scale therefore indicates the level of light or dark, the a value redness or greenness, and the $\mathrm{b}$ value yellowness or blueness. All three values are required to completely describe an object's color. Retrieved from https://www.hunterlab.com on 27.2.2019 


\subsubsection{Drum Cooling Tests}

The effect of temperature and time on the texture was tested and the results were shown on Table 6.

Table-6. Drum Cooling Tests Table

\begin{tabular}{|c|c|c|c|c|c|}
\hline \multicolumn{7}{|c|}{ Cooling Tests } \\
\hline Tests No: & Temperature & Time & Temperature $\left({ }^{\circ} \mathbf{C}\right)$ & Time (sec.) & Texture $(\mathbf{g})$ \\
\hline 1 & -1 & -1 & 25,0 & 270 & 5891,15 \\
\hline 2 & 1 & -1 & 50,0 & 270 & 6015,54 \\
\hline 3 & -1 & 1 & 25,0 & 350 & 5713,9 \\
\hline 4 & 1 & 1 & 50,0 & 350 & 5489,65 \\
\hline 5 & -1 & 0 & 25,0 & 310 & 6218,32 \\
\hline 6 & 1 & 0 & 50,0 & 310 & 5849,64 \\
\hline 7 & 0 & -1 & 37,5 & 270 & 5987,61 \\
\hline 8 & 0 & 1 & 37,5 & 350 & 6701,41 \\
\hline 9 & 0 & 0 & 37,5 & 310 & 6065,22 \\
\hline 10 & 0 & 0 & 37,5 & 310 & 6293,57 \\
\hline 11 & 0 & 0 & 37,5 & 310 & 6436,78 \\
\hline 12 & 0 & 0 & 37,5 & 310 & 6524,25 \\
\hline 13 & 0 & 0 & 37,5 & 310 & 6604,09 \\
\hline
\end{tabular}

\subsubsection{Pre-coating Tests}

The effect of coating and time variables on the texture properties was tested and shown on Table-7.

Table-7. Pre-Coating Tests Table

\begin{tabular}{|c|c|c|c|c|c|}
\hline \multicolumn{7}{|c|}{ Pre-Coating Tests } \\
\hline Tests No: & Amount of Coating & Time & Amount of Coating (\%) & Time(mins.) & Texture(g) \\
\hline 1 & -1 & -1 & 15,0 & 25 & 5317,41 \\
\hline 2 & 1 & -1 & 30,0 & 25 & 5325,51 \\
\hline 3 & -1 & 1 & 15,0 & 35 & 5916,54 \\
\hline 4 & 1 & 1 & 30,0 & 35 & 5108,93 \\
\hline 5 & -1 & 0 & 15,0 & 30 & 5890,14 \\
\hline 6 & 1 & 0 & 30,0 & 30 & 5610,25 \\
\hline 7 & 0 & -1 & 22,5 & 25 & 5789,54 \\
\hline 8 & 0 & 1 & 22,5 & 35 & 5503,25 \\
\hline 9 & 0 & 0 & 22,5 & 30 & 5747,17 \\
\hline 10 & 0 & 0 & 22,5 & 30 & 5967,94 \\
\hline 11 & 0 & 0 & 22,5 & 30 & 5924,50 \\
\hline 12 & 0 & 0 & 22,5 & 30 & 6100,18 \\
\hline 13 & 0 & 0 & 22,5 & 30 & 6019.75 \\
\hline
\end{tabular}




\subsubsection{Aging -Recrystallization Tests}

At this stage of the process, it was aimed to reach the suitable form by keeping product for a length of time in certain temperature and humidity range.

Table-8. Aging - Recrystallization Tests

Humidity, temperature

\begin{tabular}{|c|c|c|c|c|c|c|c|}
\hline \multicolumn{7}{|c|}{ Re-Crystallization Tests } & \\
\hline $\begin{array}{c}\text { Tests } \\
\text { No: }\end{array}$ & $\begin{array}{c}\text { Re- } \\
\text { crystallization } \\
\text { Room } \\
\text { Humidity }\end{array}$ & Time & Temperature & $\begin{array}{c}\text { Re- } \\
\text { crystallization } \\
\text { Room } \\
\text { Humidity (\%) }\end{array}$ & Time(mins) & Temperature( ${ }^{\circ}$ C) & $\begin{array}{c}\text { Texture } \\
\text { Strength(g) }\end{array}$ \\
\hline 1 & -1 & -1 & -1 & 20 & 12 & 15,0 & 6002,66 \\
\hline 2 & 1 & -1 & -1 & 50 & 12 & 15,0 & 4976,55 \\
\hline 3 & -1 & 1 & -1 & 20 & 72 & 15,0 & 4704,34 \\
\hline 4 & 1 & 1 & -1 & 50 & 72 & 15,0 & 5009,03 \\
\hline 5 & -1 & -1 & 1 & 20 & 12 & 30,0 & 5157,45 \\
\hline 6 & 1 & -1 & 1 & 50 & 12 & 30,0 & 4494,15 \\
\hline 7 & -1 & 1 & 1 & 20 & 72 & 30,0 & 4510,92 \\
\hline 8 & 1 & 1 & 1 & 50 & 72 & 30,0 & 3591,45 \\
\hline 9 & -1 & 0 & 0 & 20 & 42 & 22,5 & 4597,25 \\
\hline 10 & 1 & 0 & 0 & 50 & 42 & 22,5 & 4103,64 \\
\hline 11 & 0 & -1 & 0 & 35 & 12 & 22,5 & 4319,44 \\
\hline 12 & 0 & 1 & 0 & 35 & 72 & 22,5 & 4013,43 \\
\hline 13 & 0 & 0 & -1 & 35 & 42 & 15,0 & 4625,50 \\
\hline 14 & 0 & 0 & 1 & 35 & 42 & 30,0 & 3983,13 \\
\hline 15 & 0 & 0 & 0 & 35 & 42 & 22,5 & 4152,52 \\
\hline 16 & 0 & 0 & 0 & 35 & 42 & 22,5 & 4045,65 \\
\hline 17 & 0 & 0 & 0 & 35 & 42 & 22,5 & 4231,10 \\
\hline 18 & 0 & 0 & 0 & 35 & 42 & 22,5 & 4310,15 \\
\hline 19 & 0 & 0 & 0 & 35 & 42 & 22,5 & 4215,47 \\
\hline 20 & 0 & 0 & 0 & 35 & 42 & 22,5 & 4421,20 \\
\hline
\end{tabular}

\subsubsection{Hard Coating Tests}

In addition to protecting the physical form of the pre-coated product, the hard coating also contributes to the aroma, color and texture properties of the product. The hard coating stage is one of the critical points for stable values of the product.

With the composed 13 testing sets, the effects of the coating thickness and temperature variables on the humidity, texture and color properties of the product were tried to be determined at this stage of the process. 
Table-9. Hard Coating Tests

\begin{tabular}{|c|c|c|c|c|c|c|c|c|c|}
\hline \multicolumn{9}{|c|}{ Hard Coating } \\
\hline $\begin{array}{c}\text { Test } \\
\text { No }\end{array}$ & $\begin{array}{c}\text { Amount } \\
\text { of } \\
\text { Coating }\end{array}$ & $\begin{array}{c}\text { Tempe } \\
\text { rature }\end{array}$ & $\begin{array}{c}\text { Amount of } \\
\text { Coating }(\%)\end{array}$ & $\begin{array}{c}\text { Temperature } \\
\left({ }^{\circ} \mathbf{C}\right)\end{array}$ & $\begin{array}{c}\text { Strength } \\
(\mathbf{g})\end{array}$ & $\begin{array}{c}\text { Humidit } \\
\mathbf{y}(\%)\end{array}$ & $\mathbf{L}$ & $\mathbf{a}$ & $\mathbf{b}$ \\
\hline 1 & -1 & -1 & 15 & 18 & 4275,34 & 3 & 84,7 & 7,66 & 86,4 \\
\hline 2 & 1 & -1 & 30 & 18 & 4679,43 & 3,1 & 80 & 9,98 & 89,7 \\
\hline 3 & -1 & 1 & 15 & 24 & 4289,42 & 2,9 & 78,9 & 11,7 & 91,2 \\
\hline 4 & 1 & 1 & 30 & 24 & $46,80,33$ & 3 & 77,4 & 13,7 & 95,3 \\
\hline 5 & -1 & 0 & 15 & 21 & 4374,11 & 3,2 & 82 & 8,95 & 86 \\
\hline 6 & 1 & 0 & 30 & 21 & 4784,88 & 3,3 & 78,3 & 12,9 & 94,8 \\
\hline 7 & 0 & -1 & 22,5 & 18 & 4694,5 & 3,7 & 84 & 8,81 & 86,3 \\
\hline 8 & 0 & -1 & 22,5 & 24 & 4473,6 & 3,3 & 79,1 & 13,7 & 92,2 \\
\hline 9 & 0 & 0 & 22,5 & 21 & 4502,35 & 3,6 & 80,9 & 9,05 & 86,6 \\
\hline 10 & 0 & 0 & 22,5 & 21 & 4421,24 & 3,5 & 80,8 & 12,8 & 91,6 \\
\hline 11 & 0 & 0 & 22,5 & 21 & 4614,75 & 3,5 & 81,6 & 12,3 & 91,4 \\
\hline 12 & 0 & 0 & 22,5 & 21 & 4215,87 & 3,4 & 80,9 & 11,7 & 90,2 \\
\hline 13 & 0 & 0 & 22,5 & 21 & 4743,66 & 3,5 & 80,9 & 9,18 & 88,2 \\
\hline
\end{tabular}

*The L value for each scale therefore indicates the level of light or dark, the a value redness or greenness, and the $b$ value yellowness or blueness. All three values are required to completely describe an object's color. Retrieved from https://www.hunterlab.com on 27.2.2019.

\section{RESULTS \& DISCUSSIONS}

\subsection{The Results Obtained}

\subsubsection{RSM Results after Cooking}

\section{Consistency Value;}

The formula describing the effects of temperature and vacuum variables on consistency value is shown below.

Consistency $($ Force $x$ Time $)=\mathbf{9 4 2 2 , 2}+\mathbf{7 0 5 , 7} \times$ Temperature $+\mathbf{8 5 8 , 0} \times$ Vacuum $+10,9 \times$ Temperature $x$ Vacuum

According to the formula obtained, it was observed that the product consistency was changing in directly proportional to the temperature and vacuum. It was seen that both variables were $95 \%$ above the effect value.

\section{Viscosity Index Value;}

The formula describing the effects of temperature and vacuum variables on viscosity is shown below.

Viscosity $($ Force $x$ Time $)=2204,7+298 \times$ Temperature $+459 \times$ Vacuum $+77 \times$ Temperature $x$ Vacuum

According to the formula obtained, it was observed that the product viscosity changed in directly proportional with the temperature and vacuum. It was seen that both variables were $95 \%$ above the effect value. 


\section{Humidity;}

The formula describing the effects of temperature and vacuum variables on humidity of the product.

Humidity $(\%)=6,4854-0,2150 \times$ Temperature $-0,1817 \times$ Vacuum $+0,0275 \times$ Temperature x Vacuum

According to the formula obtained, it was observed that the viscosity of the product changed inversely proportional with temperature and vacuum. It was observed that both variables were $95 \%$ above the effect value.

\section{Color Value $(L, a, b)$;}

The formula describing the effects of temperature and vacuum variables on product color (L);

$\mathrm{L}=63,0062+0,357 \times$ Temperature $+0,345 \times$ Vacuum $-0,072 \times$ Temperature $x$

\section{Vacuum}

According to the formula obtained, it was observed that the product color (L) value changed in directly proportional with temperature and vacuum. It was observed that both variables were $95 \%$ above the effect value.

The formula describing the effects of temperature and vacuum variables on product color (a); $\mathrm{x}$ Vacuum

$\mathbf{a}=0,46615+0,00667 \times$ Temperature $+0,01333 \times$ Vacuum $-0,00250 \times$ Temperature

"a" value was observed to change in directly proportional with the temperature value in cooking parameters. However, this value can be ignored. Temperature does not have much effect on "a" value of the product. It was seen that vacuum value is a more effective factor than the temperature and is also a variable directly proportional to "a" value.

The vacuum variable of the test affects on a value $95 \%$ above and temperature variable has shown far below this ratio.

The formula describing the effects of temperature and vacuum variables on product color (b)

\section{Vacuum}

$b=10,5031+0,0633 \times$ Temperature $+0,1917 \times$ Vacuum - 0,0675 $\times$ Temperature $x$

"b" value was observed to change in directly proportional with the temperature value in cooking parameters. However, this value can be ignored. Temperature does not have much effect on " $b$ " value of the product. It was seen that vacuum value is more effective than the temperature and is also a variable directly proportional to " $b$ " value.

The vacuum variable of the test affects on $b$ value was $95 \%$ above and temperature variable has shown far below this ratio.

\section{Consistency Value;} consistency

The formula describing the effects of temperature and time variables on product

Consistency $($ Force $x$ Time $)=13310,0-1011,5 \times$ Temperature $\left({ }^{\circ} \mathrm{C}\right)+88,4 \times$ Time (mins.) $+182 *$ Temperature $\left({ }^{\circ} \mathrm{C}\right) \times$ Temperature $\left({ }^{\circ} \mathrm{C}\right)-43 x$ Time (mins.)xTime (mins.) $+26,5 *$ Temperature $\left({ }^{\circ} \mathrm{C}\right) \times$ Time (mins.) 
According to the formula obtained, it was observed that the product consistency value changed inversely proportional with the temperature and changed in direct proportional with the time. It was observed that both variables were $95 \%$ above the effect value on the consistency value.

It was observed that the temperature value of the test affects on consistence above $95 \%$ value and the time is less effective on consistency.

Viscosity Value;

The formula describing the effects of temperature and time variables on product viscosity

Viscosity $($ Force $x$ Time $)=4472+157 \times$ Temperature $\left({ }^{\circ} \mathrm{C}\right)-16 \times$ Time $($ mins. $)-64$ $x$ Temperature $\left({ }^{\circ} \mathrm{C}\right) \times$ Temperature $\left({ }^{\circ} \mathrm{C}\right)$ - 12 Time $(\min ) \times$ Time $(\mathrm{min})-152 \mathrm{x}$ Temperature $\left({ }^{\circ} \mathrm{C}\right) \times$ Time $(\mathrm{min})$

It has been observed that the viscosity values changed in directly proportional with the temperature value in the cooking parameters. However, this value can be ignored on the viscosity value so there is no critical effect value. It has been observed that the time is less effective factor than the temperature and it is changed inversely proportional to the viscosity value.

It has been observed that the effect of temperature value of the test on viscosity value is $70 \%$ and the time is less effective $(10 \%)$ on the viscosity value.

\subsubsection{RSM Results after Crystallization}

\section{Texture Value;}

The formula describing the effects of the amount of the sugar and time on the product texture:

Texture $(\mathrm{g})=1461,81-96,30 \times$ Amount of Sugar $-97,00 \times$ Time $(\mathrm{min})+52,3 \times$ Amount of Sugar $x$ Amount of Sugar - 18,8 x Time $(\min ) \times$ Time $(\min )+0,05 \times$ Amount of Sugar $x$ Time (min)

According to the formula obtained, it has been observed that the texture value of the product changed inversely proportional to the amount of the sugar and time. It was observed that both variables were $95 \%$ above the effect value on the consistency value.

Color Value (L, $a, b)$;

The formula describing the effects of sugar amount and time variables on product color (L);

$\mathrm{L}=$ 83,616 - 0,773 Amount of Sugar - 0,882 Time(mins.) - 1,459 Amount of SugarxAmount of Sugar1,474 Time (mins.) $x$ Time(mins.) - 0,493 Amount of Sugar $x$ Time(mins.)

According to the formula obtained, it was observed that the product color (L) value changed inversely proportional to the amount of sugar and time. It was observed that both variables were above $95 \%$ of the effect value.

The formula describing the effects of sugar amount and time variables on product color (a);

$\mathrm{a}=0,5103-0,0050 \times$ Amount of Sugar + 0,0033 $\times$ Time $(\mathrm{min})+0,0088 \times$ Amount of Sugar x Amount of Sugar - 0,0162 x Time (min) x Time (min) + 0,0075 x Amount of Sugar x Time (min) 
It has been observed that the color value (a) changed inversely proportional to the amount of the sugar and time in the crystallization parameters. However, the effect of the variable on the process can be ignored. It was observed that the time is a variable in direct proportion with "a" value and

b = 10,2831 - 0,0017 x Amount of Sugar + 0,0700 x Time $x(\min )-0,0109 \times$ Amount of Sugar x Amount of Sugar - 0,0959 x Time (min) x Time (min) + 0,0850 x Amount of Sugar $x$ Time (min)

It has been observed that the $\mathrm{b}$ value changed inversely proportional with the amount of sugar in crystallization parameters. However, the effects of the variable on the process can be ignored. It was observed that the time is a variable in direct proportion with $b$ value and the effect of this value is less on process product.

\subsubsection{RSM Results after Drum Type Cooling}

\section{Texture Value;}

The formula describing the effects of temperature and time variables on product textural value;

Texture $(\mathrm{g})=6138-78 \times$ Temperature $\left({ }^{\circ} \mathrm{C}\right)+2 \times$ Time $(\mathrm{sec})-87 \times$ Temperature $\left({ }^{\circ} \mathrm{C}\right) \times$ Time (sec)

It has been observed that the textural value changed inversely proportional with the temperature of the cooling parameters. The time is directly proportional to the hardness value. However, the effect of the two variables on the process can be ignored.

It has been observed that both variables (temperature and time) have minimum level effect on the product.

\subsubsection{RSM Results after Pre-Coating}

\section{Texture Value;}

The formula describing the effects of coating quantity and time variables on product textural value;

Texture $(\mathrm{g})=$ 5955,7 - 179,9 $\times$ Coating Quantity $(\%)+16,0 \times$ Time $(\min )-215,0 \times$ Coating Quantity (\%) x Coating Quantity (\%) - 318,8 x Time (min) x Time (min) - 203,9 x Coating Quantity (\%) x Time (min)

It has been observed that the texture value changed inversely proportional with the coating quantity in the pre-coating parameters. The time is directly proportional with the hardness value. The effect of the coating quantity on the process is less. The effects of the time on the hardness value can be ignored.

\subsubsection{RSM Results after Re-crystallization}

\section{Texture Value;}

The formula describing the effects of humidity, temperature and time variables on product textural value;

Texture $(\mathrm{g})=4473,3-280 \times$ Re-crystallization Room Humidity $(\%)-312 \times$ Time (min) $-358 \times$ Temperature $\left({ }^{\circ} \mathrm{C}\right)+134 \times$ Re-crystallization Room Humidity $(\%) x$ Time (min) - 108 x Re-crystallization Room Humidity $(\%) \times$ Time $\left({ }^{\circ} \mathrm{C}\right)-35 \times$ Time $(\min ) \times$ Temperature $\left({ }^{\circ} \mathrm{C}\right)$ 
It has been observed that the textural value changed inversely proportional with the humidity, time and temperature in the re-crystallization parameters.

\subsubsection{RSM Results of Hard Coating}

\section{Texture Value;}

The formula describing the effects of coating quantity and temperature variables on product textural value:

Texture $(\mathrm{g})=4519,2+201,0 \times$ Coating quantity $(\%)-34,3 \times$ Temperature $\left({ }^{\circ} \mathrm{C}\right)-$ 3,3 x Coating Quantity (\%) x Temperature $\left({ }^{\circ} \mathrm{C}\right)$

It has been observed that the texture value changed in directly proportional with the coating quantity at the hard coating stage. Coating quantity is shown to be a significant parameter in the hard coating. The changes that can be occurred in the quantity affect the hardness value significantly.

It has been observed that the temperature and thehardness value are nversely proportional. However, it has been proved that these changes do not significantly effect on the system.

\section{Humidity:}

The formula describing the effects of coating quantity and temperature variables on product humidity value;

Humidity $(\%)=3,3077+0,050 \times$ Coating quantity $(\%)-0,100 \times$ Temperature $\left({ }^{\circ} \mathrm{C}\right)$ $+0,000 \times$ Coating Quantity $(\%) \times$ Temperature $\left({ }^{\circ} \mathrm{C}\right)$

It has been observed that the humidity changed in direct proportional to the coating quantity in the parameters at the hard coating stage. However, it was observed that the humidity in the product did not undergo unusual change with the coating.

It was determined that the temperature changed inversely proportional with the humidity. However, these changes do not have significant effect on the product humidity mathematically.

In summary, it has been observed that the process applied in the hard coating does not lead to a significant change in the amount of normal water in the previous stages.

\section{Color Value $(L, a, b)$;}

The formula describing the effects of coating quantity and temperature variables on the product color (L) value;

$$
\mathrm{L}=\mathbf{8 0 , 7 2 6}-1,648 \times \text { Coating quantity }(\%)-2,212 \times \text { Temperature }\left({ }^{\circ} \mathrm{C}\right)+0,817 \times
$$
Coating quantity $(\%) \times$ Temperature $\left({ }^{\circ} \mathrm{C}\right)$

It has been observed that the $\mathrm{L}$ value changed inversely proportional to the coating quantity and temperature in the parameters at the stage of hard coating. It has been observed when the coating quantity increases the color tone of the product becomes darker (decreases L value) in this process.

The formula describing the effects of coating quantity and temperature variables on the product color value (a)

$\mathrm{a}=10,943+1,382 \times$ Coating quantity $(\%)+2,090 \times$ Temperature $\left({ }^{\circ} \mathrm{C}\right)-0,075 \times$ Coating quantity $(\%) \times$ Temperature $\left({ }^{\circ} \mathrm{C}\right)$ 
It has been observed that a value changed in direct proportional to the parameters at the stage of hard coating. It has been observed when the coating quantity increases the closeness of red in the color tone of the product increases in this process. It has been observed that the coating quantity is an effective variable on the product value.

The formula describing the effects of coating quantity and temperature variables on product color value (b)

$\mathrm{b}=\mathbf{8 9 , 9 9 2}+2,672 \times$ Coating quantity $(\%)+2,712 \times$ Temperature $\left({ }^{\circ} \mathrm{C}\right)+\mathbf{0 , 2 0 3} \times$ Coating quantity $(\%) \mathrm{x}$ Temperature $\left({ }^{\circ} \mathrm{C}\right)$

It has been determined that $b$ value changed in direct proportional to the coating quantity in the parameters at the stage of hard coating. It has been observed when the coating quantity increases the closeness of yellow in the color tone of the product increases (increase of b value) in this process. It has been observed that the coating quantity is an effective variable on the product.

\section{RESULTS \& DISCUSSIONS}

The process conditions of the hard coated chewy candy product were studied by using RSM Techniques. The results of the trial sets showed great similarities and gave very close values with the process parameters.

The relevant structure was obtained wth the parameters for cooking temperature of 120 ${ }^{\circ} \mathrm{C}$ and the vacuum degree of (-) 0.5 bar. The product structure did not seem to present major changes according to the results of the rapid cooling trials. The effect of the temperature on the process seemed significant in the trials. $90^{\circ} \mathrm{C}$ was a relevant temperature value.

According to the results obtained in the crystallization tests, the changes in the amount of the sugar and process time cause significant changes on the process. Texture and color spectrum parameters of the product were optimized with 5.25\% sugar ratio for 20 minutes.

The cooling trials showed that the changes in the temperature and time values do not make any significant changes in the product structure.

Pre-coating trials showed that the changes in the time values do not make any significant changes on the product structure.

According to the results obtained in the re-crystallization tests, it has been observed that the changes in the humidity, time and temperature values make significant changes on the product structure. Considering the products taken as a reference, it has been decided that the products are kept at 22.5 degrees for 42 hours at 35\% relative humidity. At $20 \%$ relative humidity, the product gets dry and becomes hard. At $50 \%$ relative humidity, the product becomes extremely soft.

According to the results obtained in the hard coating tests, coating quantity and temperature have influence on the many specifications of the product. The closest production parameters that we have reached the hardness value of the hard coating layer of the reference product are $15 \%$ coating quantity and 18 degrees. 


\section{REFERENCES}

[1] BAEK et al. (1999). Sensory perception is related to the rate of change of volatile concentration in-nose during eating of model gels. Chemical Senses, 24, 155-160.

[2] BAINES and MORRIS (1987). Flavour/taste perception in thickened systems: The effect of guar gum above and below c*. Food Hydrocolloids, 1, 197-205.

[3] CLARK (2002). Influence of hydrocolloids on flavour release and sensoryinstrumental correlations. In Phillips and Williams (Eds.), Gums and stabilisers for the food industry 11 (pp. 217-224). Cambridge: Royal Society of Chemistry.

[4] FUNAMI (2011). Next target for food hydrocolloid studies: Texture design of foods using hydrocolloid technology. Food Hydrocolloids, 25, 1904-1914.

[5] FUNAMI (2016). The formulation design of elderly special diets. Journal of Texture Studies, 47, 313-322.

[6] KOÇ and ERTEKİN (2008). Yanit yüzey yöntemi ve gida işleme uygulamalari (Response surface methodology and food processing procedures)

[7] MORRIS, E. R. (1993). Rheological and organoleptic properties of food hydrocolloids. In Nishinari and Doi (Eds.), Food hydrocolloids, structures, properties, and functions (pp. 201e210). New York: Plenum Press.

[8] WEEL et al. (2002). Flavor release and perception of flavored whey protein gels: Perception is determined by texture rather than by release. Journal of Agricultural and Food Chemistry, 50, 5149-5155.

[9] http://forum.gidagundemi.com/gidalarin-teksturel-ozellikleri-t27124.html 
EYYÜPOĞLU \& MARANGOZ \& YEŞILTEPE / RSM Method and Optimization of Hard Coated Soft Sugar Process Parameters 